Research Article

\title{
Match of Negative Stiffness and Viscous Damping in a Passive Damper for Cable Vibration Control
}

\author{
Peng Zhou $(\mathbb{D}$ ) and Qinghe Fang $(\mathbb{D}$ \\ School of Civil Engineering, Harbin Institute of Technology, Harbin 150090, China \\ Correspondence should be addressed to Qinghe Fang; qinghefang@hit.edu.cn
}

Received 29 April 2019; Revised 28 June 2019; Accepted 7 July 2019; Published 4 August 2019

Academic Editor: Matteo Aureli

Copyright (C) 2019 Peng Zhou and Qinghe Fang. This is an open access article distributed under the Creative Commons Attribution License, which permits unrestricted use, distribution, and reproduction in any medium, provided the original work is properly cited.

\begin{abstract}
Match of negative stiffness and viscous damping in a passive negative stiffness damper (NSD) is studied for the vibration control of stay cables in this paper. At first, a discrete model of the stay cable with an NSD attached perpendicularly near the support is established. Under sinusoidal excitations, forced responses of the system are derived theoretically, which results in an asymptotic form for the additional modal damping ratios. Then, experimental results are presented to verify the discrete model and the corresponding theoretical derivations. Subsequently, numerical analysis is performed further to show the optimal match of negative stiffness and viscous damping, which is a function of the attachment location. The energy dissipated by the NSD and the cable energy are analyzed, thereby demonstrating the change trend of the additional modal damping ratios. Moreover, the energy distribution along the cable is investigated to reveal the effect of the negative stiffness and viscous damping. This study demonstrates the control mechanism of negative stiffness and viscous damping in the passive damper and is of practical significance for designing the optimal match of the damper parameters for cable vibration control.
\end{abstract}

\section{Introduction}

As critical components of cable-stayed bridges, stay cables are usually extremely flexible with low inherent damping, which makes them prone to various unwanted vibrations induced by kinds of external disturbances. For example, the deck motion might interact with the cables to result in nonlinear resonance $[1,2]$. These vibrations would significantly affect the safety of stay cables by accelerating the corrosion or destroying the protection. Sometimes, even a pedestrian's nonconfidence could be caused to interrupt the normal operation of the bridges. In this regard, it turns out to be of importance to mitigate these undesired vibrations of stay cables.

To achieve such an aim, several countermeasures have been proposed, including the aerodynamic methods $[3,4]$, cross-ties [5-9], and mechanical dampers attached near the support $[10,11]$, among which negative stiffness dampers (NSDs) have been widely studied in recent years because of their superior performance. At the very beginning, the semiactive magnetorheological (MR) damper is found to yield higher effects in controlling cable vibrations [12, 13], which is a result of the negative stiffness behavior in the damping force as observed in in situ experiments [14]. Furthermore, Li et al. [15] analyzed the negative stiffness behavior in active or semiactive dampers and systematically demonstrated its ability to amplify the damper displacement response for dissipating more energy to provide a higher modal damping ratio. Moreover, Weber and Boston [16] investigated clipped viscous damping with negative stiffness numerically and experimentally. When tuned properly, additional modal damping was twice as much as the case of only optimal viscous damping. After that, an approximate applicable collocated method was developed for efficient mitigation of stay cable multimode vibrations based on the control force under clipped linear quadratic regulators [17].

The negative stiffness provided by semiactive dampers depends on the real-time feedback and power supply, which makes the entire system complex and unreliable. To draw these drawbacks, passive NSDs were suggested to replace the 
semiactive ones. For example, prepressed springs were incorporated to produce negative stiffness behavior [18-23]. As shown by the theoretical analysis, more damping was added to stay cables by a self-contained highly compressed spring in parallel with a viscous damper [21]. Furthermore, numerical and experimental results indicated that a negative stiffness damper, which consisted of two pressed springs and an oil damper, provided a larger modal damping ratio to the cable regardless of single-mode and multimode vibrations [22]. Even for the cable network, this kind of NSD exhibited superior damping enhancement for two stay cables simultaneously through interconnecting them together [23]. Magnetic NSDs using the magnetic interaction to produce negative stiffness behavior are also developed and investigated for the cable vibration mitigation [24, 25]. Kalathur and Lakes [26] proposed a postbuckled column NSD, which could achieve high structural damping combined with high initial stiffness at small amplitudes. Lu et al. [27] and Wang et al. [28] utilized the inertial mass to realize negative stiffness for cable vibration control.

In the above studies, much attention was paid to the design and realization of passive NSDs. The control mechanism and the optimal match of negative stiffness and viscous damping in the passive damper are seldom mentioned. This paper investigates the optimal match of the negative stiffness and viscous damping, followed by revelation of their control mechanism for stay cables from the perspective of energy. Initially, a discrete model with infinite degrees is established to describe the stay cable with an NSD located close to the support. Steady-state forced responses of the system under harmonic loads are derived, and additional modal damping ratios are presented approximately. Then, experimental tests are presented to compare with the above derivations. After verifying the model, numerical simulation is conducted further to study the relationship between negative stiffness and viscous damping in a passive damper for the optimal control of stay cables. The energy dissipated by the passive NSD and the cable energy, which show the changing law of additional modal damping, are analyzed numerically. Furthermore, the spatial distribution of vibrational energy along the cable is formulated to reveal the effect of negative stiffness and viscous damping. Finally, conclusions from the current study are addressed.

\section{Finite Degrees of Discrete Model for the Stay Cable with a Passive NSD}

2.1. Equation of Motion for the System. A discrete model with $n+1$ masses connected by $n$ springs, as shown in Figure 1, is explored to investigate the dynamic behavior of a stay cable. The mass on two supports is $m / 2$, while on the other place is $m$. Each spring has the identical length $l$ and tension $T$ in the horizontal condition. The passive NSD with negative stiffness $k_{\mathrm{d}}$ and viscous damping $c_{\mathrm{d}}$ is located at the node $n_{\mathrm{d}}$ close to the left support, while the external excitation $F_{\mathrm{e}}(t)$ acts at the node $n_{\mathrm{e}}$ near the right support. Neglecting the gravity and flexural effects, only the transverse vibration $y_{i}$ for the $i$ th node is considered.

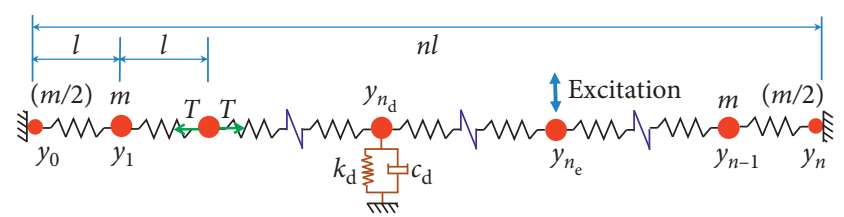

FIGURE 1: Discrete model of a stay cable with a passive NSD attached in the transverse direction.

For small deflections, three adjacent nodes $i-1, i$, and $i+1$ are described in Figure 2. Based on d'Alembert's principle, the motion equation for the node $i\left(1 \leq i \leq n-1, \neq n_{\mathrm{d}}, n_{\mathrm{e}}\right)$ in the transverse direction yields

$$
m \ddot{y}_{i}+T \sin \theta_{i-1}-T \sin \theta_{i}=0,
$$

where $\sin \theta_{i-1}$ and $\sin \theta_{i}$ are approximated as

$$
\begin{aligned}
\sin \theta_{i-1} & \approx \frac{y_{i}-y_{i-1}}{l}, \\
\sin \theta_{i} & \approx \frac{y_{i+1}-y_{i}}{l},
\end{aligned}
$$

when $\left|y_{i}-y_{i-1}\right| / l \ll 1$ and $\left|y_{i+1}-y_{i}\right| / l \ll 1$ are satisfied. Further simplification leads to

$$
\ddot{y}_{i}+\frac{T}{l m}\left(-y_{i-1}+2 y_{i}-y_{i+1}\right)=0 .
$$

With the damping force, the equation of motion for the node $n_{\mathrm{d}}$ changes into

$$
\ddot{y}_{n_{\mathrm{d}}}+\frac{T}{l m}\left(-y_{n_{\mathrm{d}}-1}+2 y_{n_{\mathrm{d}}}-y_{n_{\mathrm{d}}+1}\right)=-\frac{c_{\mathrm{d}}}{m} \dot{y}_{n_{\mathrm{d}}}-\frac{k_{\mathrm{d}}}{m} y_{n_{\mathrm{d}}} .
$$

Similarly, at the node $n_{\mathrm{e}}$, it can be obtained that

$$
\ddot{y}_{n_{\mathrm{e}}}+\frac{T}{l m}\left(-y_{n_{\mathrm{e}}-1}+2 y_{n_{\mathrm{e}}}-y_{n_{\mathrm{e}}+1}\right)=\frac{F_{\mathrm{e}}(t)}{m} .
$$

The nodes 0 and $n$ are clamped to the left and the right support, respectively. Hence, the boundary conditions

$$
\begin{aligned}
& y_{0}=0, \\
& y_{n}=0,
\end{aligned}
$$

are always satisfied, which results in [29]

$$
\begin{aligned}
& \omega_{r}=2 \sqrt{\frac{T}{l m}} \sin \frac{r \pi}{2 n}, \\
& u_{i}^{r}=\sin i \frac{r \pi}{n},
\end{aligned}
$$

where $\omega_{r}$ is the $r$ th modal angular frequency of the undamped discrete cable model and $u_{i}^{r}$ is the corresponding amplitude of the $r$ th mode at node $i$.

Rewriting in the vector form, the modal shape for the $r$ th mode becomes

$$
\mathbf{u}^{r}=\left[\begin{array}{llll}
u_{1}^{r} & u_{2}^{r} & \cdots & u_{n-1}^{r}
\end{array}\right],
$$

which has the orthogonal relation 


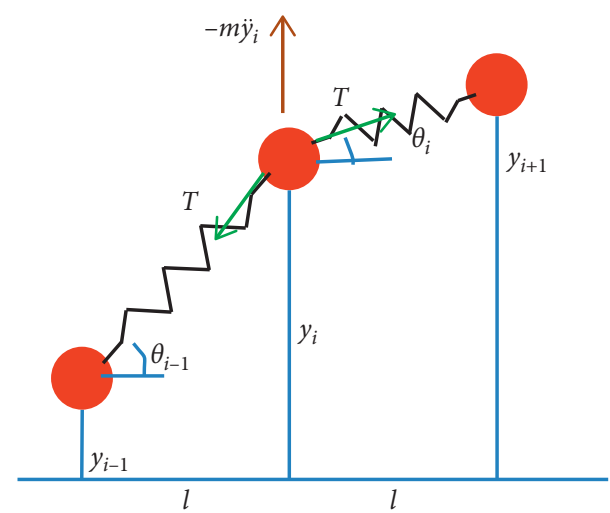

Figure 2: Force and motion diagram for the $i$ th node $\left(1<i<n, \neq n_{\mathrm{d}}, n_{\mathrm{e}}\right)$.

$$
\mathbf{u}^{r} \cdot \mathbf{u}^{s}= \begin{cases}\frac{(n-1)}{2}, & r=s, \\ 0, & r \neq s .\end{cases}
$$

2.2. Steady-State Responses under Sinusoidal Excitation. Sinusoidal excitation is assumed to act on the node $n_{\mathrm{e}}$ as

$$
F_{\mathrm{e}}(t)=F \sin \omega_{j} t
$$

where $\omega_{j}$ is the $j$ th modal angular frequency depicted in equation (7) and $F$ is the amplitude of the external excitation.

Then, the motion equation for the system is rewritten in the matrix form as

$$
\ddot{\mathbf{y}}+\mathbf{K y}=\mathbf{L}_{\mathrm{d}} F_{\mathrm{d}}(t)+\mathbf{L}_{\mathrm{e}} F_{\mathrm{e}}(t)
$$

where $\mathbf{y}=\left[\begin{array}{llll}y_{1} & y_{2} & \cdots & y_{n-1}\end{array}\right]^{T}$ is the displacement vector of $n-1$ nodes; $\ddot{\mathbf{y}}$ is the corresponding acceleration; $\mathbf{L}_{\mathrm{d}}=\left[\begin{array}{lllll}0 & \cdots & 1 & \cdots & 0\end{array}\right]^{T}$ is the damper location vector in which only the $n_{\mathrm{d}}$ element is unity; $\mathbf{L}_{\mathrm{e}}=\left[\begin{array}{lllll}0 & \cdots & 1 & \cdots & 0\end{array}\right]^{T}$ is the excitation position vector in which the $n_{\mathrm{e}}$ element is unity, while others are zero; and $\mathbf{K}$ is the stiffness matrix:

$$
\mathbf{K}=\frac{T}{\operatorname{lm}}\left[\begin{array}{ccccc}
2 & -1 & & & \\
-1 & 2 & -1 & & \\
& -1 & \ddots & \ddots & \\
& & \ddots & \ddots & -1 \\
& & & -1 & 2
\end{array}\right] \text {, }
$$

which satisfies the orthogonality relation

$$
\mathbf{u}^{r} \cdot \mathbf{K} \cdot \mathbf{u}^{s}= \begin{cases}2(n-1) \sin ^{2} \frac{r \pi}{2 n}, & r=s, \\ 0, & r \neq s .\end{cases}
$$

After reaching steady-state vibration, the system response has the following form:

$$
\mathbf{y}=\left[\begin{array}{llll}
\mathbf{u}^{1} & \mathbf{u}^{2} & \cdots & \mathbf{u}^{n-1}
\end{array}\right]\left\{\begin{array}{c}
a_{1} \sin \omega_{j} t+b_{1} \cos \omega_{j} t \\
a_{2} \sin \omega_{j} t+b_{2} \cos \omega_{j} t \\
\vdots \\
a_{n-1} \sin \omega_{j} t+b_{n-1} \cos \omega_{j} t
\end{array}\right\} .
$$

Substitution of equation (15) into (12) leads to a linear algebraic equation giving the solution of $a_{1}, a_{2}, \ldots, a_{n-1}$ and $b_{1}, b_{2}, \ldots, b_{n-1}$ as follows:

$$
\begin{aligned}
a_{r}=\frac{2}{n-1} \frac{1}{\omega_{r}^{2}-\omega_{j}^{2}} \frac{1}{u_{n_{\mathrm{d}}}^{j}}\left(u_{n_{\mathrm{d}}}^{j} u_{n_{\mathrm{e}}}^{r}-u_{n_{\mathrm{e}}}^{j} u_{n_{\mathrm{d}}}^{r}\right) \frac{F}{m}, \\
\quad r=1,2, \ldots, n-1, r \neq j,
\end{aligned}
$$

$$
\begin{aligned}
a_{j} & =\frac{2}{n-1} \frac{1}{\left(u_{n_{\mathrm{d}}}^{j}\right)^{2}} \sum_{r=1, r \neq j}^{n-1} \frac{u_{n_{\mathrm{d}}}^{r}}{\omega_{r}^{2}-\omega_{j}^{2}}\left(u_{n_{\mathrm{e}}}^{j} u_{n_{\mathrm{d}}}^{r}-u_{n_{\mathrm{d}}}^{j} u_{n_{\mathrm{e}}}^{r}\right) \frac{F}{m} \\
& +\frac{u_{n_{\mathrm{e}}}^{j}}{\left(u_{n_{\mathrm{d}}}^{j}\right)^{2}} \frac{k_{\mathrm{d}}}{k_{\mathrm{d}}^{2}+c_{\mathrm{d}}^{2} \omega_{j}^{2}} F,
\end{aligned}
$$

$$
b_{r}=0 \text {, }
$$

$$
b_{j}=-\frac{u_{n_{\mathrm{e}}}^{j}}{\left(u_{n_{\mathrm{d}}}^{j}\right)^{2}} \frac{c_{\mathrm{d}} \omega_{j}}{k_{\mathrm{d}}^{2}+c_{\mathrm{d}}^{2} \omega_{j}^{2}} F .
$$

Hence, the response of each node in the discrete model can be obtained. In particular, the displacement of the node $n_{\mathrm{d}}$ with the NSD attached is

$$
y_{n_{\mathrm{d}}}=\frac{u_{n_{\mathrm{e}}}^{j}}{u_{n_{\mathrm{d}}}^{j}} \frac{F}{\sqrt{k_{\mathrm{d}}^{2}+c_{\mathrm{d}}^{2} \omega_{j}^{2}}} \sin \left(\omega_{j} t-\varphi\right),
$$

in which $\varphi$ is the phase difference depicted as

$$
\varphi=\arctan \frac{c_{\mathrm{d}} \omega_{j}}{k_{\mathrm{d}}}
$$

2.3. Additional Modal Damping Ratios for the Cable. Using the displacement on the node $n_{\mathrm{d}}$, the energy dissipated by the NSD in one period of the $j$ th mode is obtained as

$$
\begin{aligned}
\Delta E_{j} & =\int_{0}^{\left(2 \pi / \omega_{j}\right)}\left(c_{\mathrm{d}} \dot{y}_{n_{\mathrm{d}}}+k_{\mathrm{d}} y_{n_{\mathrm{d}}}\right) \cdot \dot{y}_{n_{\mathrm{d}}} d t \\
& =\left(\frac{u_{n_{\mathrm{e}}}^{j}}{u_{n_{\mathrm{d}}}^{j}}\right)^{2} \frac{\pi c_{\mathrm{d}} \omega_{j}}{k_{\mathrm{d}}^{2}+c_{\mathrm{d}}^{2} \omega_{j}^{2}} F^{2} .
\end{aligned}
$$

Meanwhile, the potential energy of the stay cable in the $j$ th mode is 


$$
\begin{aligned}
E_{j} & =\max \left\{\frac{1}{2} \mathbf{y}^{T} \mathbf{K} \mathbf{y}\right\} \\
& \approx \frac{n-1}{4} m \omega_{j}^{2}\left\{\frac{\sum^{2}}{m^{2}}\right. \\
& \left.+\frac{1}{k_{\mathrm{d}}^{2}+c_{\mathrm{d}}^{2} \omega_{j}^{2}}\left[2 \frac{u_{n_{\mathrm{e}}}^{j}}{\left(u_{n_{\mathrm{d}}}^{j}\right)^{2}} \frac{\sum}{m} k_{\mathrm{d}}+\frac{\left(u_{n_{\mathrm{e}}}^{j}\right)^{2}}{\left(u_{n_{\mathrm{d}}}^{j}\right)^{4}}\right]\right\} F^{2},
\end{aligned}
$$

in which $\sum=(2 / n-1)\left(1 /\left(u_{n_{\mathrm{d}}}^{j}\right)^{2}\right) \sum_{r=1, r \neq j}^{n-1}\left(u_{n_{\mathrm{d}}}^{r} /\left(\omega_{r}^{2}-\omega_{j}^{2}\right)\right)$ $\left(u_{n_{\mathrm{e}}}^{j} u_{n_{\mathrm{d}}}^{r}-u_{n_{\mathrm{d}}}^{j} u_{n_{\mathrm{e}}}^{r}\right)$. is

Then, the $j$ th modal damping ratio provided by the NSD

$$
\begin{aligned}
\xi_{j}= & \frac{\Delta E_{j}}{4 \pi E_{j}}=\left(\frac{u_{n_{\mathrm{e}}}^{j}}{u_{n_{\mathrm{d}}}^{j}}\right)^{2} \frac{m}{(n-1) \omega_{j} \Sigma^{2}} \\
& \cdot \frac{c_{\mathrm{d}}}{\left[k_{\mathrm{d}}+\left(m u_{n_{\mathrm{e}}}^{j} / \sum\left(u_{n_{\mathrm{d}}}^{j}\right)^{2}\right)\right]^{2}+\omega_{j}^{2} c_{\mathrm{d}}^{2}} .
\end{aligned}
$$

Setting the derivative of $\xi_{j}$ with respect to $c_{\mathrm{d}}$ equal to zero, the modal damping ratio gains its peak value when

$$
c_{\mathrm{d}}^{\mathrm{opt}}=\frac{1}{\omega_{j}}\left|k_{\mathrm{d}}+\frac{m}{\sum} \frac{u_{n_{\mathrm{e}}}^{j}}{\left(u_{n_{\mathrm{d}}}^{j}\right)^{2}}\right|,
$$

in which $c_{\mathrm{d}}^{\text {opt }}$ is the optimal damper coefficient maximizing the modal damping ratio, and the corresponding optimal damper stiffness is

$$
k_{\mathrm{d}}^{\mathrm{opt}}=-\frac{m}{\sum} \frac{u_{n_{\mathrm{e}}}^{j}}{\left(u_{n_{\mathrm{d}}}^{j}\right)^{2}} .
$$

\section{Experimental Validation}

3.1. Equivalent Parameters for the NSD. To suppress the cable vibration, Zhou and Li [22] developed a passive NSD, which is composed of two prepressed springs and an oil damper. The damping force consists of the negative stiffness and the Coulomb friction as

$$
f_{\mathrm{NSD}}=k_{\mathrm{d}} x+F_{r} \operatorname{sgn}(\dot{x}),
$$

where $f_{\mathrm{NSD}}$ is the damping force, $k_{\mathrm{d}}=-2.73 \mathrm{~N} / \mathrm{mm}$ is the negative stiffness approximately determined by the NSD's geometrical configuration, $F_{r}=17 \mathrm{~N}$ is the Coulomb friction level, and $x$ and $\dot{x}$ are the displacement and velocity of the damper, respectively.

Making the dissipation energy per cycle the same, an equivalent viscous damping is adopted to replace the Coulomb friction part of the NSD when the cable-damper system vibrates in the $j$ th mode as follows:

$$
c_{\text {eq }}=\frac{4 F_{r}}{\pi \omega_{j} A_{\mathrm{d}}},
$$

in which $c_{\text {eq }}$ is the viscous damping coefficient and $A_{\mathrm{d}}$ is the amplitude of displacement at the damper position.

Figure 3 shows the equivalent hysteretic loops for one experimental case. The areas surrounded by the two curves are the same. Equivalent viscous damping coefficient $c_{\text {eq }}$ is inversely proportional to the product of the $j$ th modal angular frequency $\omega_{j}$ and the damper's displacement amplitude $A_{\mathrm{d}}$ when the Coulomb friction force is kept unchanged. In the following verification, analytical results using the equivalent viscous damping coefficients will be compared with the experimental results.

3.2. Discretization of the Continuous Cable. The length of the scaled stay cable used in the experiment [22] was $14 \mathrm{~m}$ with the mass per unit length of $1.33 \mathrm{~kg} / \mathrm{m}$. The tension force was adjusted to $10 \mathrm{kN}$. Two damper locations were considered in the tests, which are $0.535 \mathrm{~m}$ and $1.06 \mathrm{~m}$ to the left anchorage, respectively. An electric shaker was employed to produce sinusoidal excitation forces acting at $0.345 \mathrm{~m}$ from the right anchorage. For each damper location, the first and the second modal vibration was excited for the cable. After reaching the steady state, the electric shaker was cut off, and then the cable began its free vibration with exponential decaying amplitudes, which are explored to identify the additional modal damping ratios provided by the passive NSD.

For the discrete model, the parameters, such as the node mass $\mathrm{m}$ and the length $l$, are equal to the total mass and total length divided by the node number $n$. Then, the natural frequencies are determined by equation (7). Figure 4(a) depicts the frequency ratio of the discrete model to the continuous cable for the first three modes. With the node number $n$ increase, the ratio converges to unity quickly and the relative error decreases dramatically. When the node number $n$ is larger than 100, the relative error becomes less than $0.1 \%$. Hence, $n=200$ is utilized in the discrete model to guarantee the precision. As shown in Figure 4(b), the first three modal frequencies of the discrete model are almost the same as the experimental results.

3.3. Verification for the Displacement Response and Additional Modal Damping Ratio. The excitation force in the experiment is used to calculate the theoretical responses of the discrete model. The excitation position is $n_{\mathrm{e}}=195$. Figure 5 compares the first modal displacement responses of the discrete model with experimental results when the damper is located at $n_{\mathrm{d}}=8$. The calculated displacement response at the damper location coincides well with the experimental result. Moreover, the calculated displacement response at the midspan of the cable agrees well with the experimental result.

Specially, the relationship of displacement amplitude to damping at the damper's location is shown in Figure 6. The vertical axis is the dimensionless displacement amplitude according to equation (17). Under different levels of damping, experimental results are very close to the theoretical curve. The value of dimensionless displacement 


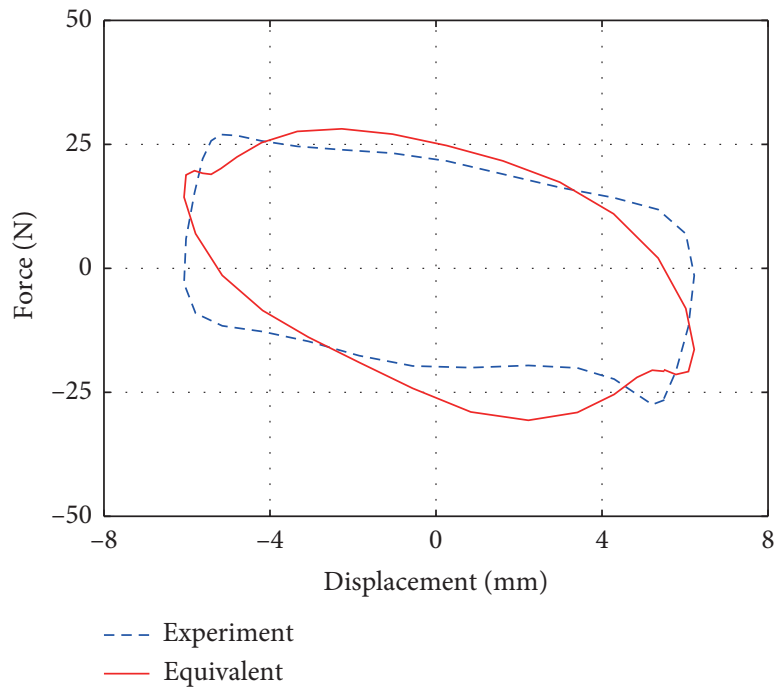

FIGURE 3: Equivalent hysteretic loops for the experimental NSD.

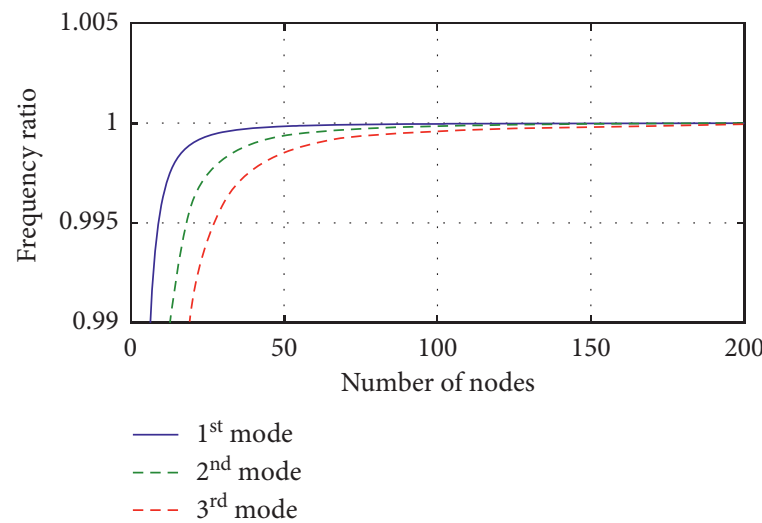

(a)

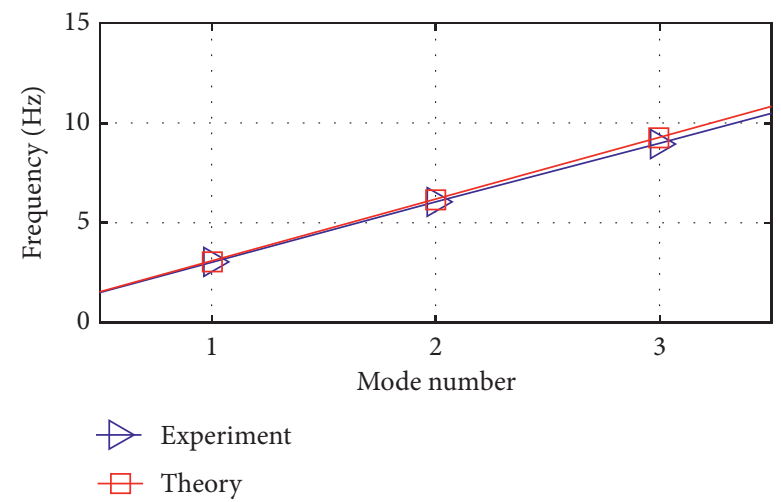

(b)

Figure 4: (a) Frequency ratios for the first three modes; (b) comparison of the natural frequencies with $n=200$ to the experimental results.

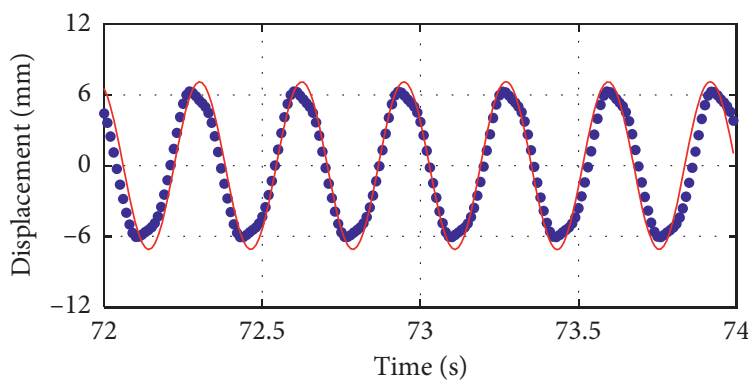

- Experiment

- Theory

(a)

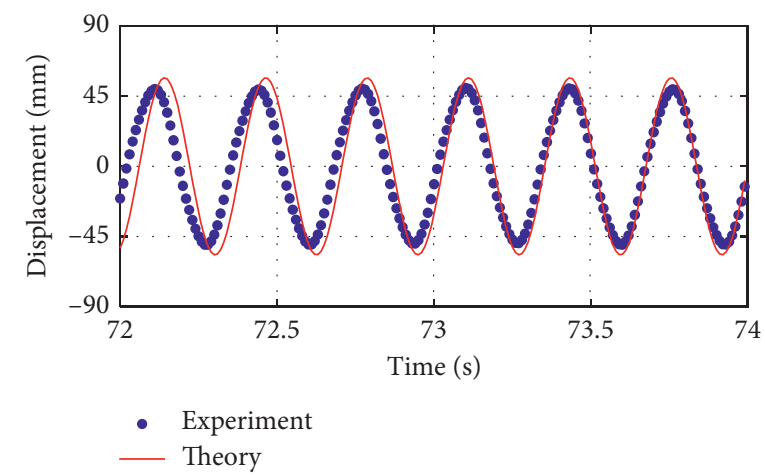

(b)

FIGURE 5: Displacements of the cable under the first modal vibration with the NSD: (a) damper location; (b) midspan.

decreases with increasing damping $c_{\mathrm{d}} \omega$, as high damping will clamp the cable to make the damper's location response small.
The additional modal damping ratios provided by the NSD are demonstrated in Figure 7. In general, the experimental damping ratios at two locations agree with the 


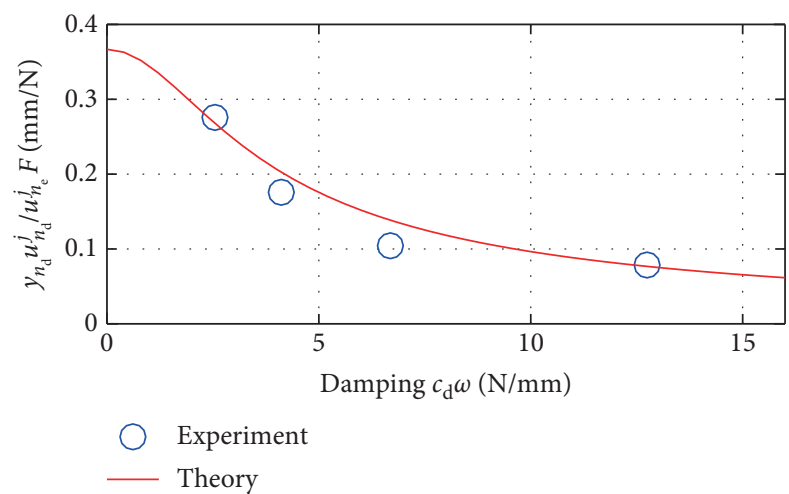

FIGURE 6: Relationship of displacement amplitude to damping at the damper's location.

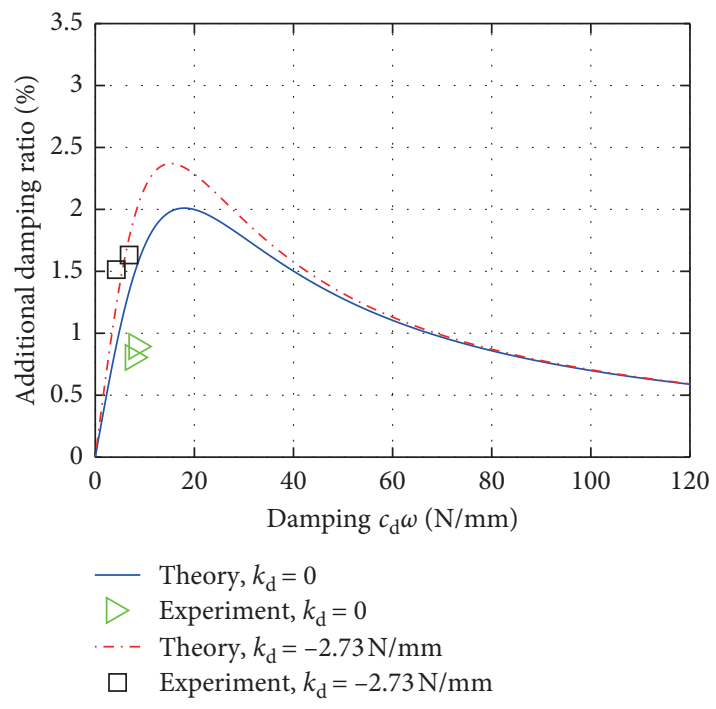

(a)

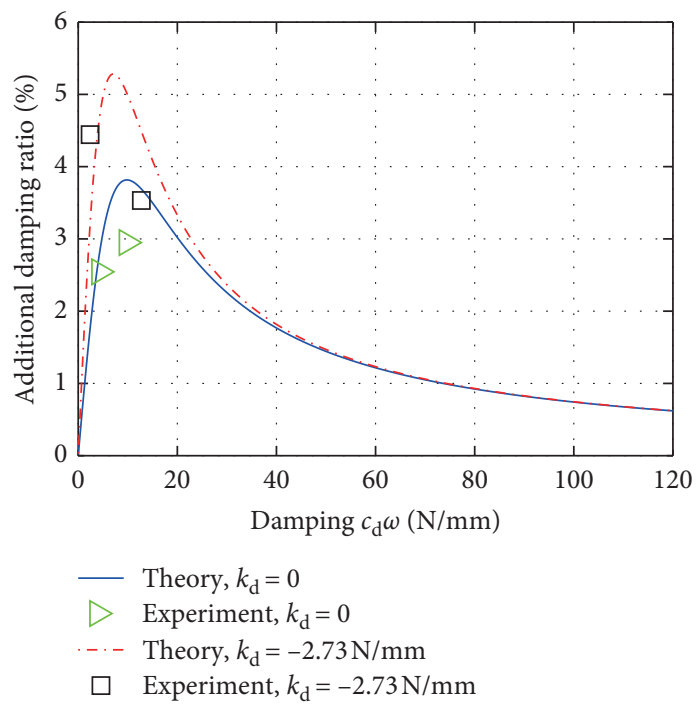

(b)

Figure 7: Additional damping ratios provided by the damper: (a) $n_{\mathrm{d}}=8$; (b) $n_{\mathrm{d}}=15$.

theoretical curves according to the above derivation, although some points deviate a little largely. Comparing with damper stiffness $k_{\mathrm{d}}=0$, more damping ratios can be achieved when $k_{\mathrm{d}}=-2.73 \mathrm{~N} / \mathrm{mm}$, which means the negative stiffness is beneficial to enhance damping ratios. However, the beneficial effect varies with the level of the damping $c_{\mathrm{d}} \omega$.

The absolute increment of the additional damping ratio reaches its maximum near the region of optimal damping values. To be different, the curves of the relative increment of the additional damping ratio and damping are plotted in Figure 8. The vertical axis represents the relative ratio increased by the negative stiffness $k_{\mathrm{d}}=-2.73 \mathrm{~N} / \mathrm{mm}$ to the case $k_{\mathrm{d}}=0$. The relative increment decreases with the increasing damping. For small values of damping, the negative stiffness remarkably increases the damping ratio. Also, a larger damper position enhances the damping ratio much more. For large values of damping, the negative stiffness has little effect on the improvement of the damping ratio wherever the damper is located.

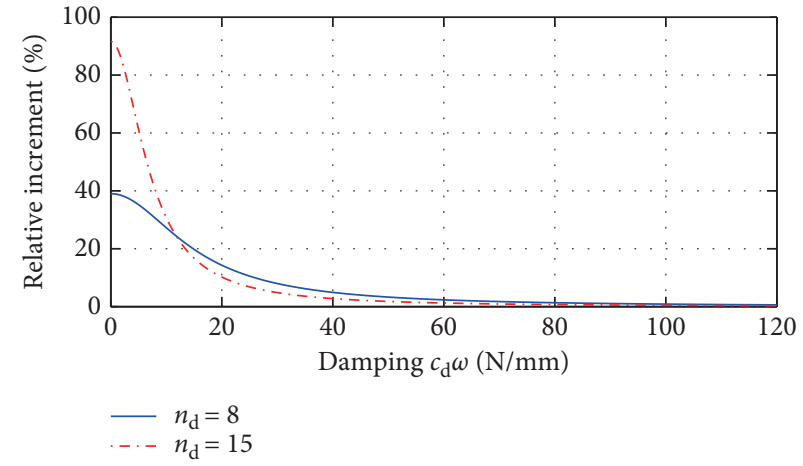

FIGURE 8: Relative increment of the additional damping ratio with negative stiffness $k_{\mathrm{d}}=-2.73 \mathrm{~N} / \mathrm{mm}$.

\section{Numerical Analysis}

The discrete model of the stay cable with an NSD has been deduced theoretically and validated experimentally in the former sections. In this section, numerical analysis will be 
further performed to reveal the optimal match of the negative stiffness and viscous damping based on the aforementioned derivations of the discrete model. Moreover, the influence and mechanism of the negative stiffness and viscous damping will be demonstrated in the perspective of energy.

4.1. Optimal Negative Stiffness and Viscous Damping. The effect of the excitation position on the optimal negative stiffness for the cable is analyzed firstly. As shown in Figure 9, the optimal negative stiffness for the first and second modes is kept unchanged when the excitation position $n_{\mathrm{e}} / n$ varies from 0.8 to about 1 . So, the excitation position has no effect on the optimal negative stiffness.

Being different from the excitation position, the damper location mainly determines the value of the optimal negative stiffness. Figure 10 plots the curves of the optimal negative stiffness, which is inversely proportional to the damper location, agreeing with the following:

$$
k_{\mathrm{d}}^{\mathrm{opt}}=-\frac{T}{n_{\mathrm{d}} l} .
$$

The relationship between the optimal damping and the negative stiffness is further described in Figure 11. When the negative stiffness reaches its optimum, the corresponding optimal damping is zero for mode 1 and mode 2. For other values of negative stiffness, the optimal damping $c_{\mathrm{d}}^{\text {opt }}$ differs with the mode number. And less damping is needed for the higher mode.

The phase difference, as depicted in equation (18), caused by the optimal negative stiffness and damping at the damper location is depicted in Figure 12. The phase difference is zero when the optimal damping is zero, which means that the response of the damper location and the excitation are kept unchanged simultaneously. In contrast, when the damping tends to infinity, this phase difference approaches $-\pi / 4$, regardless of the damper location.

4.2. Energy Dissipated by the NSD. From the initial state, the excitation force maintains inputting energy until the cableNSD system reaches its steady-state vibration. Under the steady state, the cable's mechanical energy stays constant, while the excitation energy is always dissipated by the damper. Obviously, the cable mechanical energy or the energy dissipated by the NSD depends on the parameters of the damping and stiffness. The change tendencies of the first modal vibration are shown in Figure 13, in which the horizontal axis is the damping and the vertical axis is the cable mechanical energy or the energy dissipated by the NSD itself. Four different levels of the damper stiffness, $k_{\mathrm{d}}=2 k_{\mathrm{d}}^{\mathrm{opt}}, k_{\mathrm{d}}^{\mathrm{opt}}, 0$, and $\left|k_{\mathrm{d}}^{\mathrm{opt}}\right|$, are employed to compare with each other. When the damper stiffness is negative, such as $k_{\mathrm{d}}=2 k_{\mathrm{d}}^{\mathrm{opt}}$ or $k_{\mathrm{d}}^{\mathrm{opt}}$, the cable mechanical energy increases with the damping. The energy dissipated by the NSD rises until reaching a peak value and then decreases with the damping. Especially, for the optimal negative stiffness and zero damping, the cable mechanical energy becomes zero in Figure 13(b). In contrast, the cable mechanical energy tends

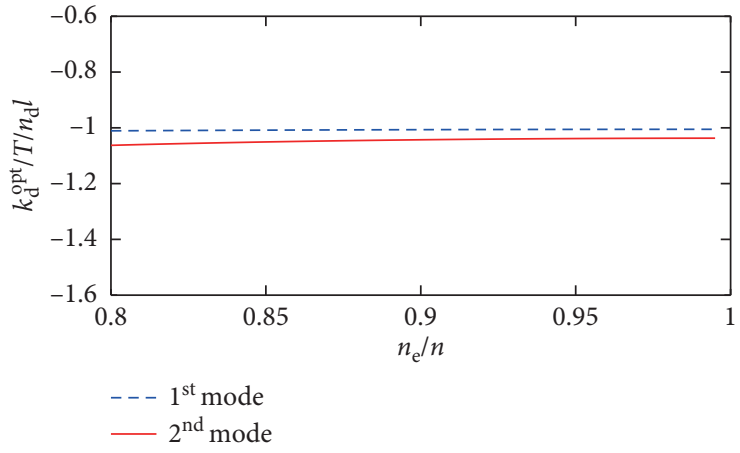

FIgURE 9: Change trend of the optimal negative stiffness to the excitation position.

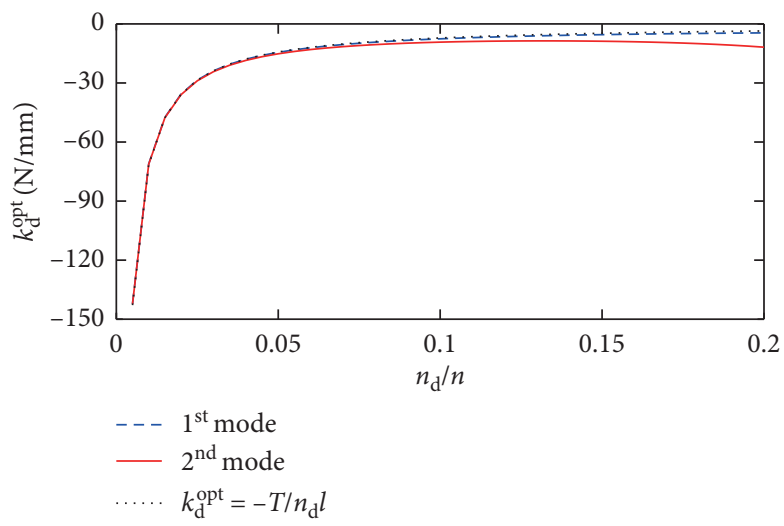

Figure 10: Change trend of the optimal negative stiffness to the damper location.

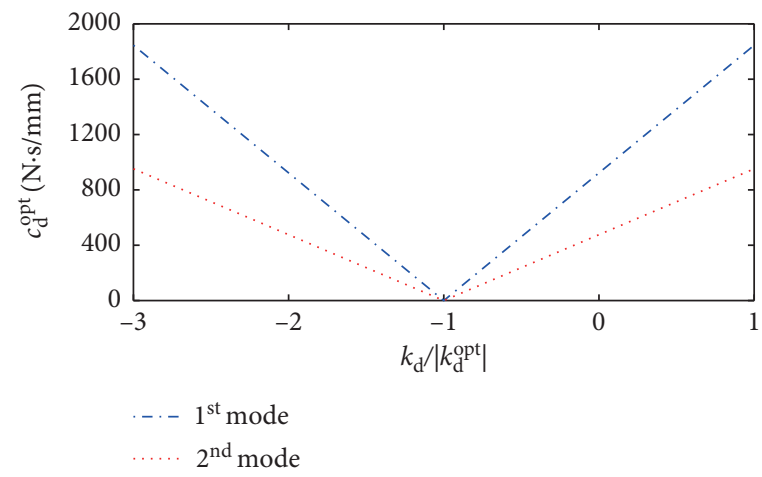

FIgURE 11: Optimal damping corresponding to the negative stiffness.

to infinity when the damping is zero and then decreases with the damping, as shown in both Figures 13(c) and 13(d), under the nonnegative conditions. When the damping tends to zero, the dissipated energy tends to infinity for $k_{\mathrm{d}}=0$ while tends to zero for $k_{\mathrm{d}}=\left|k_{\mathrm{d}}^{\mathrm{opt}}\right|$. For all the values of stiffness, the cable mechanical energy moves toward a constant value at last, while the energy dissipated reduces to zero as the damping increases to infinity. 


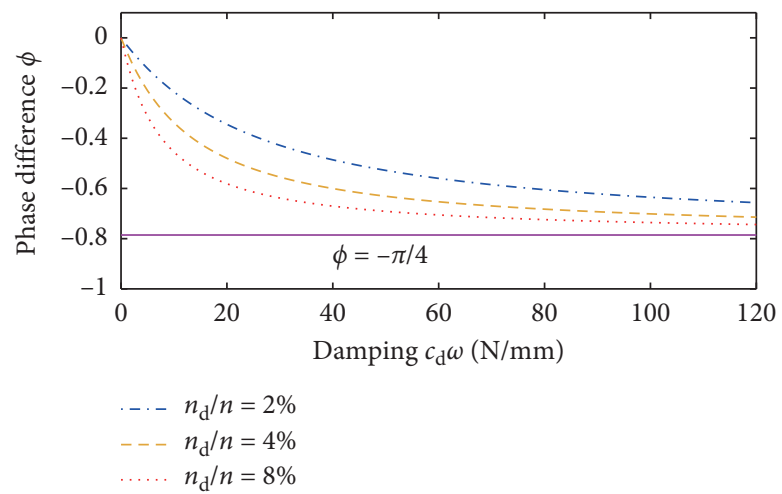

Figure 12: Phase difference at the damper location.

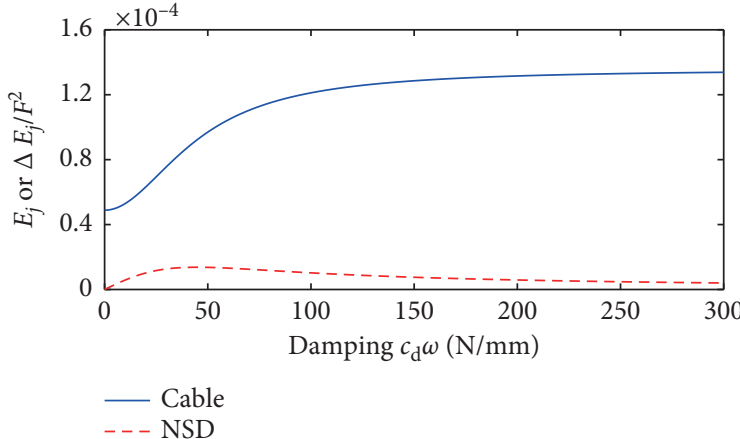

(a)

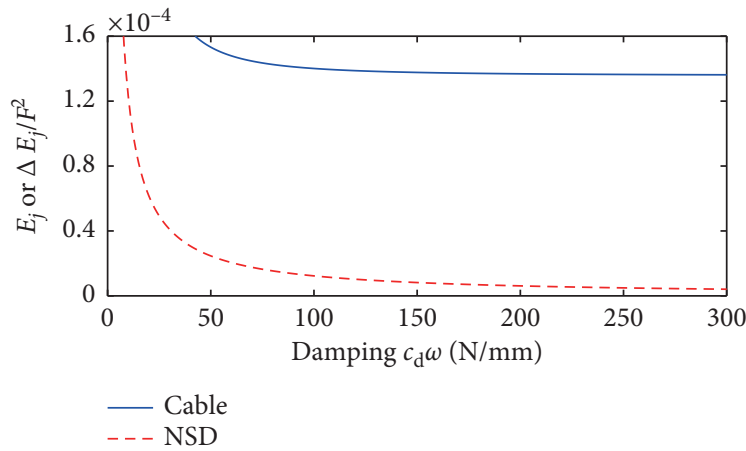

(c)

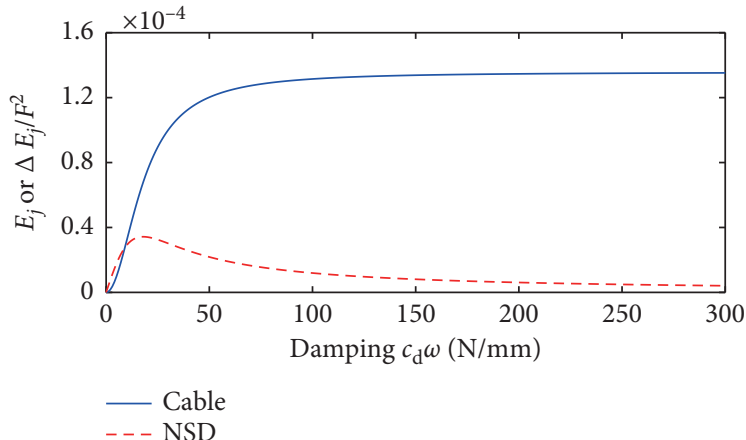

(b)

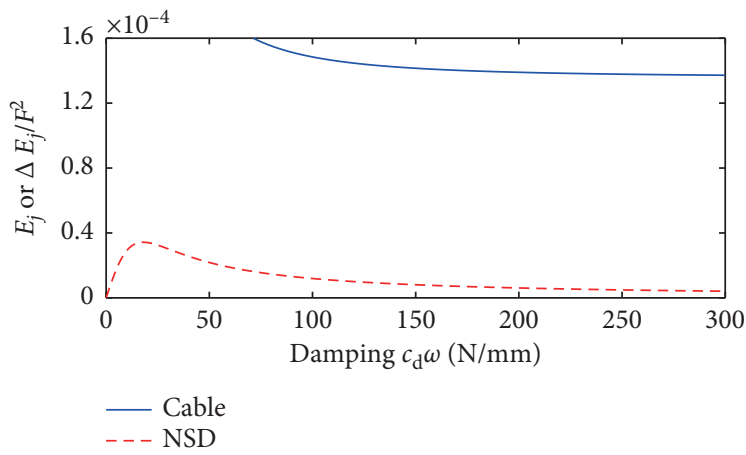

(d)

FIGURE 13: Change trend of the cable mechanical energy or the energy dissipated by the NSD to the damping with different levels of stiffness: (a) $k_{\mathrm{d}}=2 k_{\mathrm{d}}^{\mathrm{opt}}$; (b) $k_{\mathrm{d}}=k_{\mathrm{d}}^{\mathrm{opt}}$; (c) $k_{\mathrm{d}}=0$; (d) $k_{\mathrm{d}}=\left|k_{\mathrm{d}}^{\mathrm{opt}}\right|$.

Figure 14 shows the change trend of the cable mechanical energy or dissipated energy with the normalized stiffness under four levels of viscous damping. It can be seen clearly that the minimum cable mechanical energy is zero when the normalized stiffness is negative unity and the damping is zero in Figure 14(a). In general, the cable mechanical energy decreases with stiffness when $k_{\mathrm{d}} / k_{\mathrm{d}}^{\mathrm{opt}} \leq-1$ is satisfied. For $k_{\mathrm{d}} / k_{\mathrm{d}}^{\text {opt }}>-1$, the cable mechanical energy firstly increases to the peak value and then declines with the increasing stiffness. The viscous damping can remarkably reduce the maximum cable energy, as shown in Figures 14(a)-14(d). With the same damping, the cable energy is generally much less when the stiffness is negative. The energy dissipated by the NSD achieves the maximum value around the $k_{\mathrm{d}} /\left|k_{\mathrm{d}}^{\mathrm{opt}}\right|=0$ region.

The results of other modes are similar to those of the first mode, so the curves of other modes are not drawn here. Under the steady-state forced vibration, the cable mechanical energy means the vibration intensity of the cable. Only the energy dissipated by the NSD is not enough to evaluate the control performance. The cable mechanical energy has a minimum value of zero under the condition of optimal negative stiffness and zero damping. This zero mechanical energy means that the cable has the weakest 


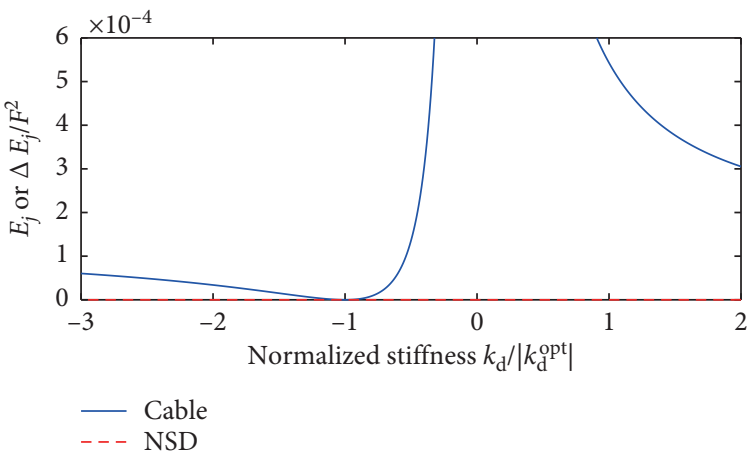

(a)

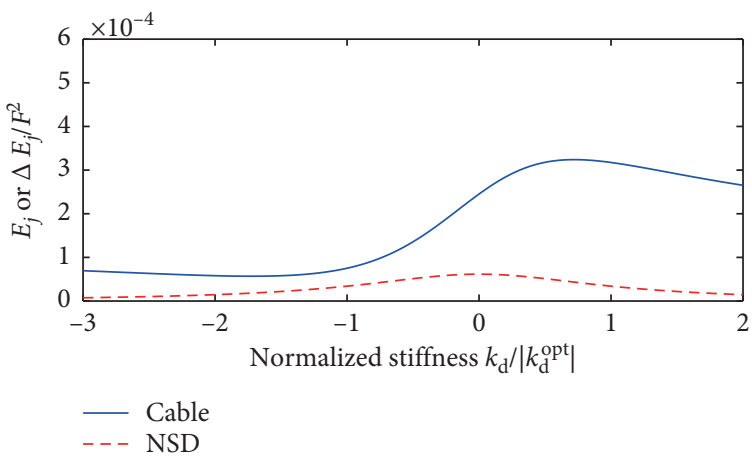

(c)

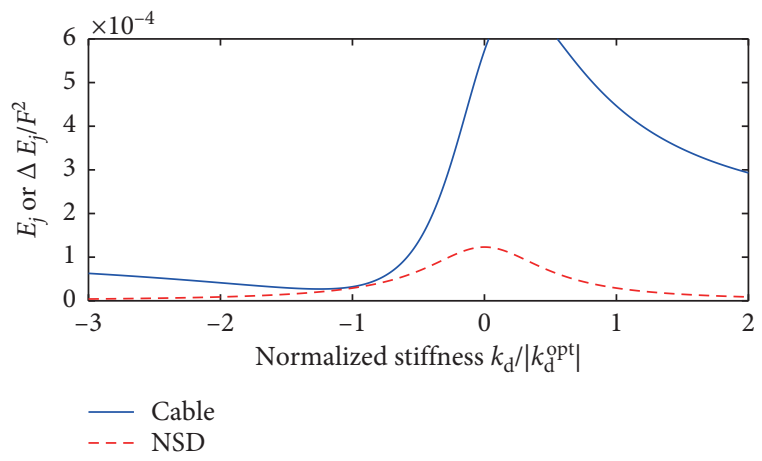

(b)

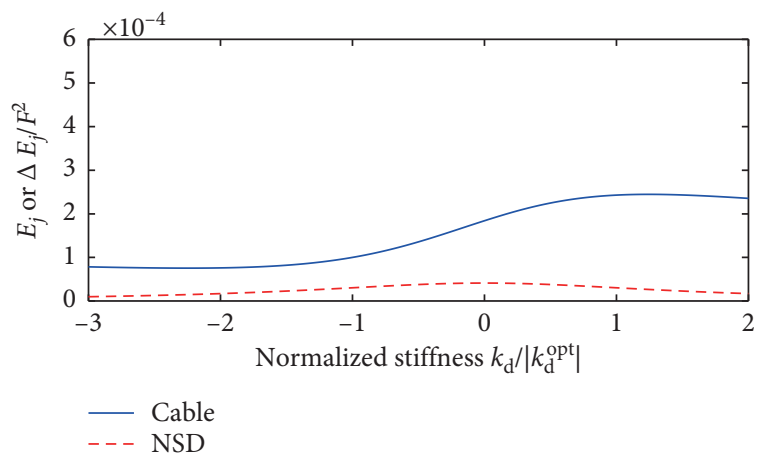

(d)

FIGURE 14: Change trend of the cable mechanical energy or the energy dissipated by the NSD to the stiffness with different levels of damping: (a) $c_{\mathrm{d}} \omega=0$; (b) $c_{\mathrm{d}} \omega=10 \mathrm{~N} / \mathrm{mm}$; (c) $c_{\mathrm{d}} \omega=20 \mathrm{~N} / \mathrm{mm}$; (d) $c_{\mathrm{d}} \omega=30 \mathrm{~N} / \mathrm{mm}$.

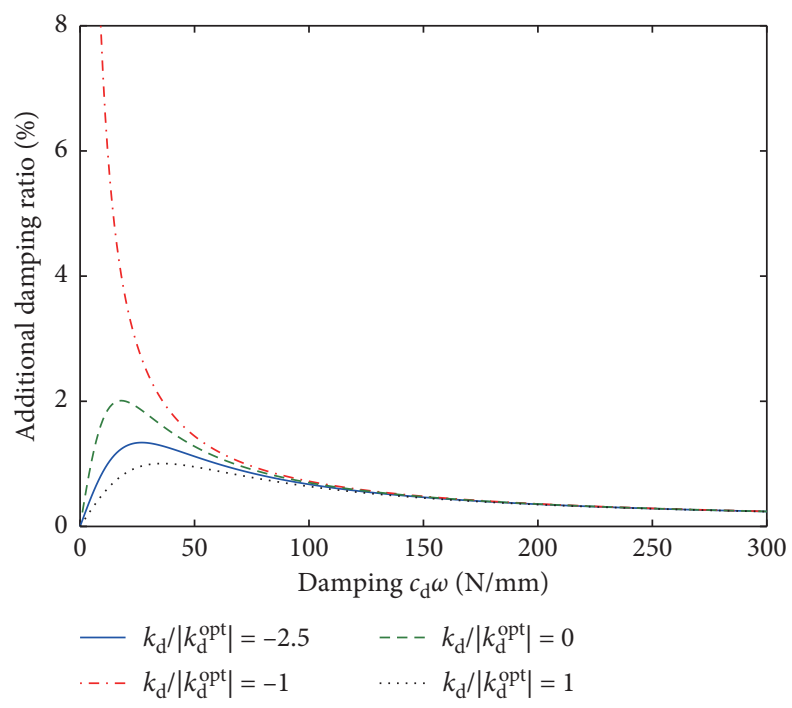

Figure 15: Additional modal damping ratio for the stay cable with various levels of stiffness.

vibration. In other words, the parameters for best control performance are the combination of the optimal negative stiffness and zero damping.

Figure 15 plots the additional modal damping ratio for the stay cable with various levels of stiffness, which could be achieved by altering the stiffness coefficient of the springs and their compression degree in the proposed damper in [22], while the viscous damping depends on the oil damper. So, the proposed apparatus could be effectively employed for a real cable by choosing proper parameters. For $k_{\mathrm{d}} /\left|k_{\mathrm{d}}^{\mathrm{opt}}\right|=-1$, the additional modal damping ratio reaches infinity under zero damping. When the damping 


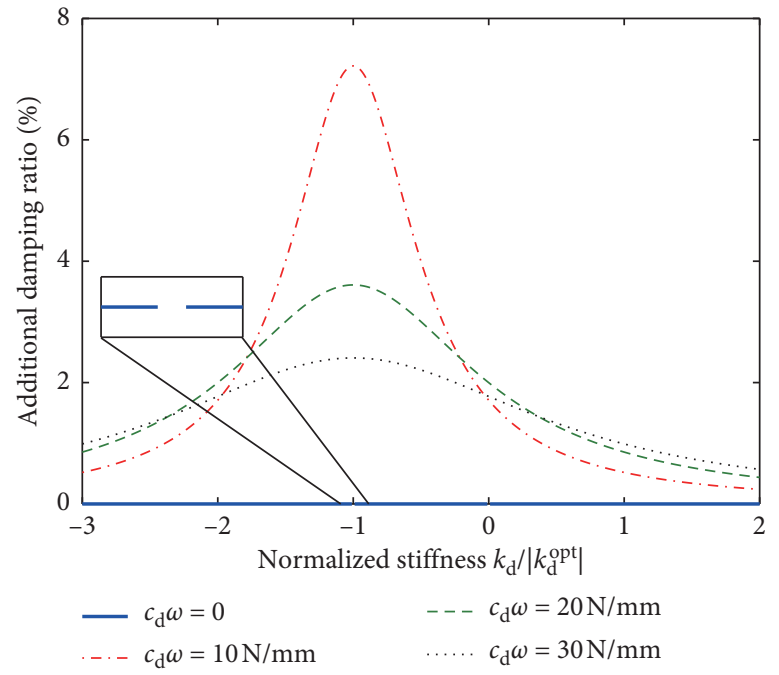

Figure 16: Additional modal damping ratio for the stay cable with various levels of damping.

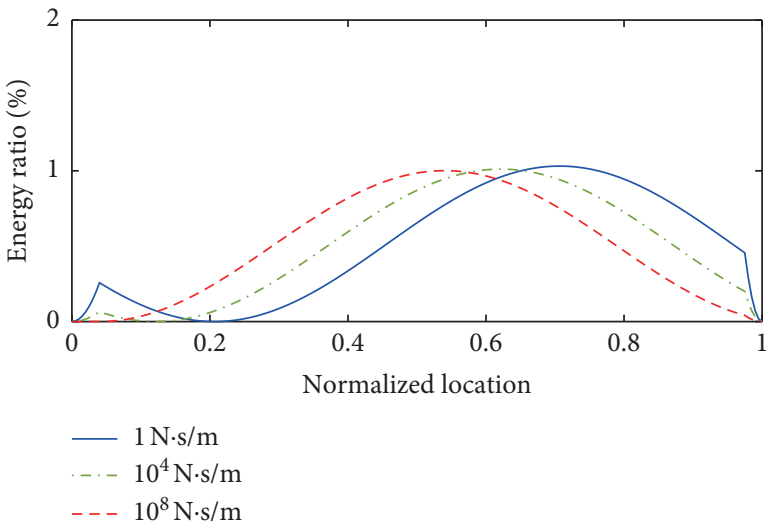

(a)

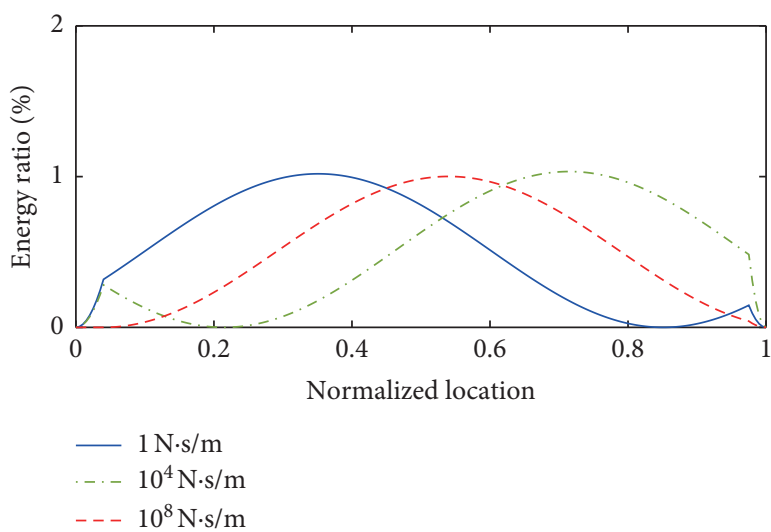

(c)

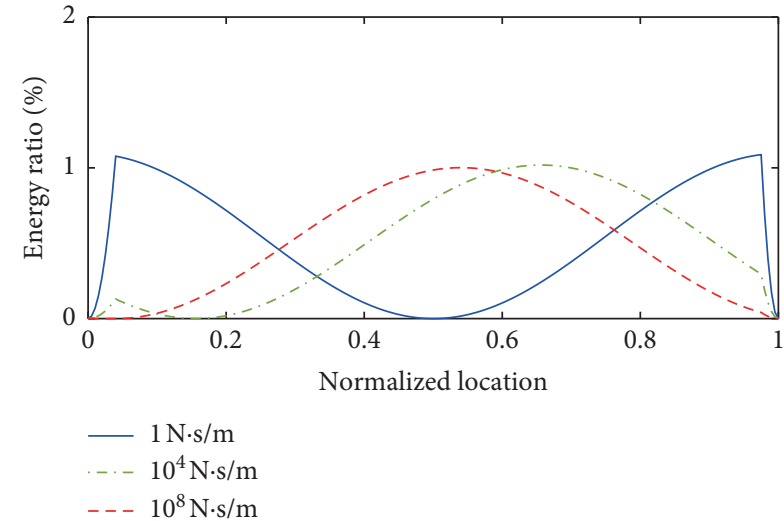

(b)

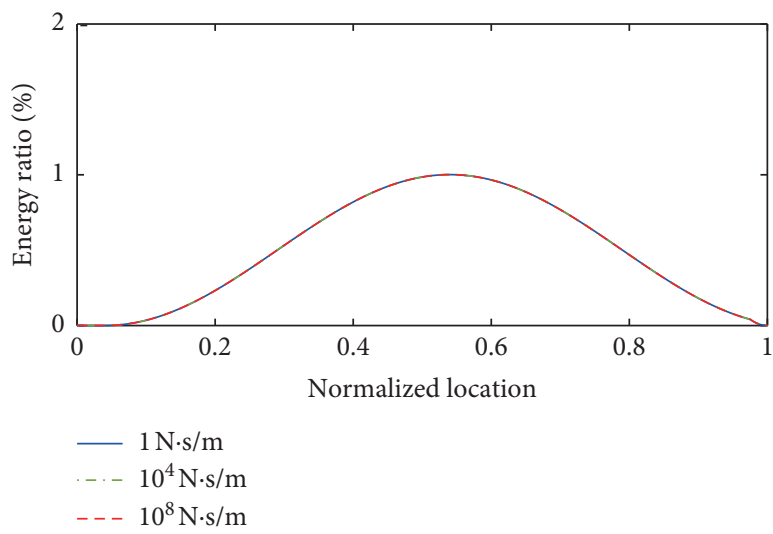

(d)

Figure 17: Distribution of the cable mechanical energy under the first modal vibration: (a) $k_{\mathrm{d}} /\left|k_{\mathrm{d}}^{\mathrm{opt}}\right|=-1.2 ;$ (b) $k_{\mathrm{d}} /\left|k_{\mathrm{d}}^{\mathrm{opt}}\right|=-1$; (c) $k_{\mathrm{d}} /\left|k_{\mathrm{d}}^{\mathrm{opt}}\right|=-0.8$; (d) $k_{\mathrm{d}} /\left|k_{\mathrm{d}}^{\mathrm{opt}}\right|=0$.

$c_{\mathrm{d}} \omega \geq 100 \mathrm{~N} / \mathrm{mm}$, the additional modal damping ratio is basically unchanged regardless of the level of stiffness.

Furthermore, Figure 16 compares the additional modal damping ratio with various levels of damping. For the same level of damping, the additional modal damping ratio achieves its peak value at the point $k_{\mathrm{d}} /\left|k_{\mathrm{d}}^{\mathrm{opt}}\right|=-1$. That is to say, the optimal negative stiffness enhances the effect of damping remarkably. 


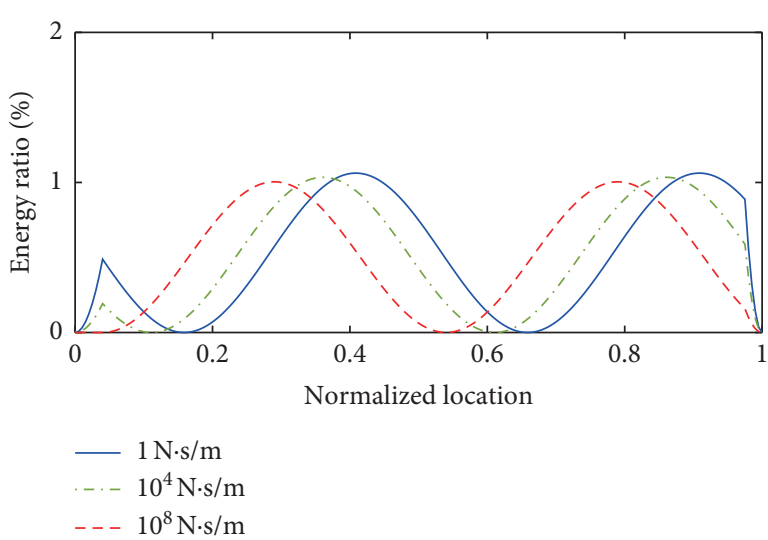

(a)

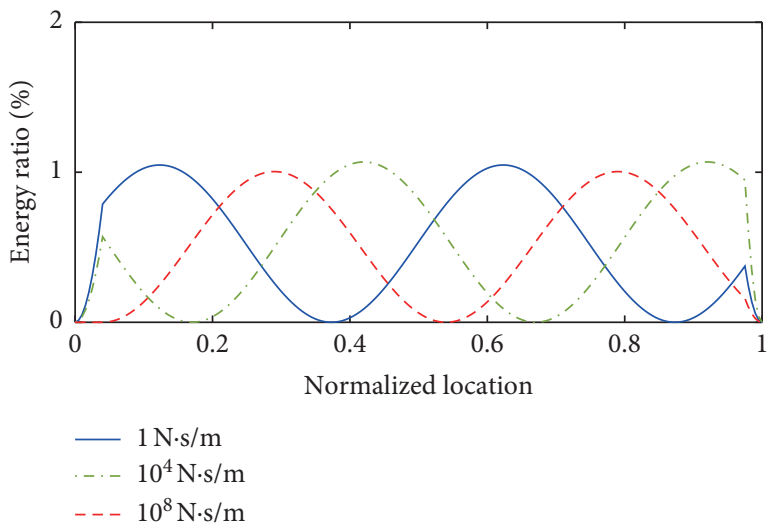

(c)

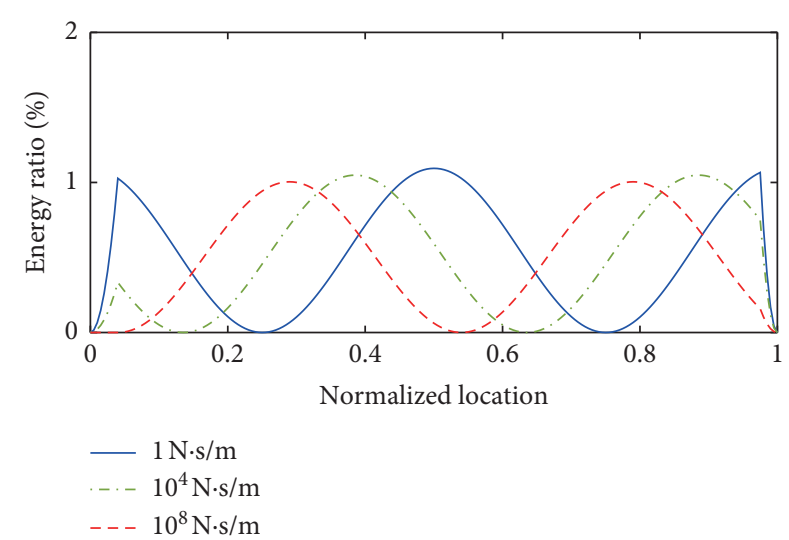

(b)

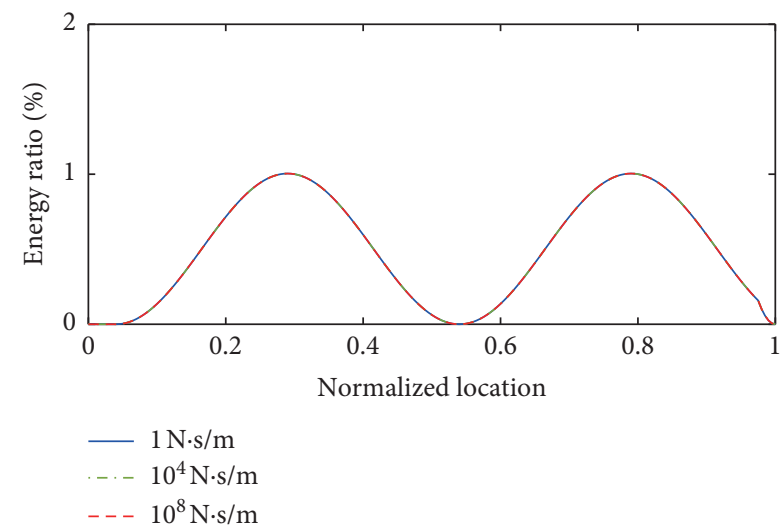

(d)

Figure 18: Distribution of the cable mechanical energy under the second modal vibration: (a) $k_{\mathrm{d}} /\left|k_{\mathrm{d}}^{\mathrm{opt}}\right|=-1.2 ;$ (b) $k_{\mathrm{d}} /\left|k_{\mathrm{d}}^{\mathrm{opt}}\right|=-1$; (c) $k_{\mathrm{d}} /\left|k_{\mathrm{d}}^{\mathrm{opt}}\right|=-0.8 ;$ (d) $k_{\mathrm{d}} /\left|k_{\mathrm{d}}^{\mathrm{opt}}\right|=0$.

4.3. Energy Distribution along the Cable. This section will analyze the energy distribution along the cable when the NSD is attached for vibration control.

The energy ratio of each node in the discrete model is demonstrated in Figure 17. The horizontal axis is the dimensionless position, in which zero represents the left support and unity corresponds to the right support. The vertical axis is the energy ratio of each node to the total mechanical energy of the cable. The negative stiffness and viscous damping significantly affect the energy distribution along the cable and increase the energy at the damper location. In particular, the energy ratio at the damper location is only $0.3 \%$ when $k_{\mathrm{d}} /\left|k_{\mathrm{d}}^{\mathrm{opt}}\right|=-1.2$ and $c_{\mathrm{d}}=1 \mathrm{~N} \cdot \mathrm{s} / \mathrm{m}$. For the case $k_{\mathrm{d}} /\left|k_{\mathrm{d}}^{\mathrm{opt}}\right|=-1$, this ratio increases to $1 \%$, while the energy ratio at the cable midspan declines to zero, which is obviously different from the original first mode. When the damping $c_{d}=10^{8} \mathrm{~N} \cdot \mathrm{s} / \mathrm{m}$, the energy distribution is similar to that of the first mode and the peak value of the energy ratio appears at the midspan of the cable.

Under the second modal vibration, the energy ratio at the damper location is increased by the negative stiffness, as shown in Figure 18. In particular, the energy ratio at the damper location reaches $1 \%$, which is its peak value, when $k_{\mathrm{d}} /\left|k_{\mathrm{d}}^{\mathrm{opt}}\right|=-1$ and the damping $c_{\mathrm{d}}$ approaches zero. For the high damping, energy distribution along the cable is unchanged and even the negative stiffness is optimal.

\section{Conclusions}

The match of negative stiffness and viscous damping for cable vibration mitigation is investigated in this paper. A discrete model for the stay cable with an NSD was firstly established, and the system dynamic characteristics, including the forced steady-state vibration and additional modal damping ratio, were performed theoretically. After that, experimental results were utilized to verify the discrete model and the corresponding derivations. Then, numerical analysis was carried out further to reveal the effect of negative stiffness and viscous damping in the cable vibration mitigation. Moreover, the energy dissipated by the NSD and the energy distribution along the cable were evaluated. Based on the results of this study, the following conclusions could be drawn.

A discrete model, which can effectively describe the system dynamic behavior, was established for the stay cable with an NSD attached near the support. The forced steadystate vibration response and the additional modal damping ratio based on this model agree with the experimental results well. 
The cable energy and the energy dissipated by the NSD depend on the negative stiffness and viscous damping. With the optimal negative stiffness and zero damping, the cable mechanical energy declines to the weakest vibration condition.

In particular, the match of negative stiffness and viscous damping also has a significant impact on the energy distribution along the cable. More precisely, the negative stiffness concentrates the energy to the damper location. For the optimal negative stiffness and zero damping, the energy ratio at the damper location approaches its peak value.

\section{Data Availability}

The data used to support the findings of this study are included within the article.

\section{Conflicts of Interest}

The authors declare that they have no conflicts of interest.

\section{Acknowledgments}

This study was financially supported by Grants 51808175 and 51808172 from the National Natural Science Foundation of China and Projects 2018M640297 and 2018M641833 funded by the China Postdoctoral Science Foundation.

\section{References}

[1] Y. Cong, H. Kang, and T. Guo, "Planar multimodal 1:2:2 internal resonance analysis of cable-stayed bridge," $\mathrm{Me}$ chanical Systems and Signal Processing, vol. 120, pp. 505-523, 2019.

[2] T. Guo, H. Kang, L. Wang, and Y. Zhao, "An inclined cable excited by a non-ideal massive moving deck: an asymptotic formulation," Nonlinear Dynamics, vol. 95, no. 1, pp. 749-767, 2019.

[3] Y. Miyata, H. Yamada, and T. Hojo, "Experimental study on aerodynamic characteristics of cables with patterned surface," Journal of Structural Engineering, vol. 40A, pp. 1065-1076, 1994.

[4] M. Gu and X. Du, "Experimental investigation of rain-windinduced vibration of cables in cable-stayed bridges and its mitigation," Journal of Wind Engineering and Industrial Aerodynamics, vol. 93, no. 1, pp. 79-95, 2005.

[5] H. Yamaguchi and H. D. Nagahawatta, "Damping effects of cable cross ties in cable-stayed bridges," Journal of Wind Engineering and Industrial Aerodynamics, vol. 54-55, pp. 35-43, 1995.

[6] L. Caracoglia and N. P. Jones, "In-plane dynamic behavior of cable networks. Part 1: formulation and basic solutions," Journal of Sound and Vibration, vol. 279, no. 3-5, pp. 969-991, 2005.

[7] L. Caracoglia and N. P. Jones, "In-plane dynamic behavior of cable networks. Part 2: prototype prediction and validation," Journal of Sound and Vibration, vol. 279, no. 3-5, pp. 9931014, 2005.

[8] G. F. Giaccu, B. Barbiellini, and L. Caracoglia, "Parametric study on the nonlinear dynamics of a three-stay cable network under stochastic free vibration," Journal of Engineering $\mathrm{Me}$ chanics, vol. 141, no. 6, Article ID 04014166, 2015.
[9] L. Caracoglia, G. F. Giaccu, and B. Barbiellini, "Estimating the standard deviation of eigenvalue distributions for the nonlinear free-vibration stochastic dynamics of cable networks," Meccanica, vol. 52, no. 1-2, pp. 197-211, 2017.

[10] B. M. Pacheco, Y. Fujino, and A. Sulekh, "Estimation curve for modal damping in stay cables with viscous damper," Journal of Structural Engineering, vol. 119, no. 6, pp. 1961-1979, 1993.

[11] S. Krenk, "Vibrations of a taut cable with an external damper," Journal of Applied Mechanics, vol. 67, no. 4, pp. 772-776, 2000.

[12] R. E. Christenson, B. F. Spencer Jr., and E. A. Johnson, "Experimental verification of smart cable damping," Journal of Engineering Mechanics, vol. 132, no. 3, pp. 268-278, 2006.

[13] E. A. Johnson, G. A. Baker, B. F. Spencer Jr., and Y. Fujino, "Semiactive damping of stay cables," Journal of Engineering Mechanics, vol. 133, no. 1, pp. 1-11, 2007.

[14] H. Li, M. Liu, J. Li, X. Guan, and J. Ou, "Vibration control of stay cables of the Shandong Binzhou Yellow River highway bridge using magnetorheological fluid dampers," Journal of Bridge Engineering, vol. 12, no. 4, pp. 401-409, 2007.

[15] H. Li, M. Liu, and J. Ou, "Negative stiffness characteristics of active and semi-active control systems for stay cables," Structural Control and Health Monitoring, vol. 15, no. 2, pp. 120-142, 2008

[16] F. Weber and C. Boston, "Clipped viscous damping with negative stiffness for semi-active cable damping," Smart Materials and Structures, vol. 20, no. 4, 13 pages, Article ID 045007, 2011.

[17] F. Weber and H. Distl, "Semi-active damping with negative stiffness for multi-mode cable vibration mitigation: approximate collocated control solution," Smart Materials and Structures, vol. 24, no. 11, Article ID 115015, 14 pages, 2015.

[18] A. A. Sarlis, D. T. R. Pasala, M. C. Constantinou, A. M. Reinhorn, S. Nagarajaiah, and D. P. Taylor, "Negative stiffness device for seismic protection of structures," Journal of Structural Engineering, vol. 139, no. 7, pp. 1124-1133, 2013.

[19] D. Pasala, A. Sarlis, A. Reinhorn, S. Nagarajaiah, M. C. Constantinou, and D. Taylor, "Simulated bilinearelastic behavior in a SDOF elastic structure using negative stiffness device: experimental and analytical study," Journal of Structural Engineering, vol. 140, no. 2, Article ID 04013049, 2014.

[20] M. Liu, P. Zhou, and H. Li, "Investigation on a novel selfcentering negative stiffness damper based on combination of shape memory alloy and pre-pressed springs," Journal of Aerospace Engineering, vol. 31, no. 6, Article ID 04018100, 2018.

[21] L. Chen, L. Sun, and S. Nagarajaiah, "Cable with discrete negative stiffness device and viscous damper: passive realization and general characteristics," Smart Structures and Systems, vol. 15, no. 3, pp. 627-643, 2015.

[22] P. Zhou and H. Li, "Modeling and control performance of a negative stiffness damper for suppressing stay cable vibrations," Structural Control and Health Monitoring, vol. 23, no. 4, pp. 764-782, 2016.

[23] P. Zhou, M. Liu, H. G. Xiao, and H. Li, "Feasibility of using a negative stiffness damper to two interconnected stay cables for damping enhancement," International Journal of Structural Stability and Dynamics, vol. 19, no. 6, article 1950058, 2019.

[24] X. Shi and S. Y. Zhu, "Magnetic negative stiffness dampers," Smart Materials and Structures, vol. 24, no. 7, Article ID 072002, 2015.

[25] X. Shi, S. Y. Zhu, and B. F. Spencer Jr., "Experimental study on passive negative stiffness damper for cable vibration 
mitigation," Journal of Engineering Mechanics, vol. 143, no. 9, Article ID 04017070, 2017.

[26] H. Kalathur and R. S. Lakes, "Column dampers with negative stiffness: high damping at small amplitude," Smart Materials and Structures, vol. 22, no. 8, Article ID 084013, 2013.

[27] L. Lu, Y. F. Duan, B. F. Spencer Jr., X. Lu, and Y. Zhou, "Inertial mass damper for mitigating cable vibration," Structural Control Health Monitoring, vol. 24, no. 10, Article ID 1986, 2017.

[28] Z. H. Wang, H. Gao, B. Q. Fan, and Z. Q. Chen, "Inertial mass damper for vibration control of cable with sag," Journal of Low Frequency Noise, Vibration and Active Control, Article ID 146134841881496, 2018.

[29] M. Geradin and D. Rixen, Mechanical Vibrations, vol. 122, Cambridge University Press, Chichester, UK, 3rd edition, 2015. 


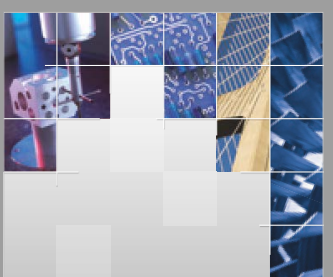

\section{Enfincering}
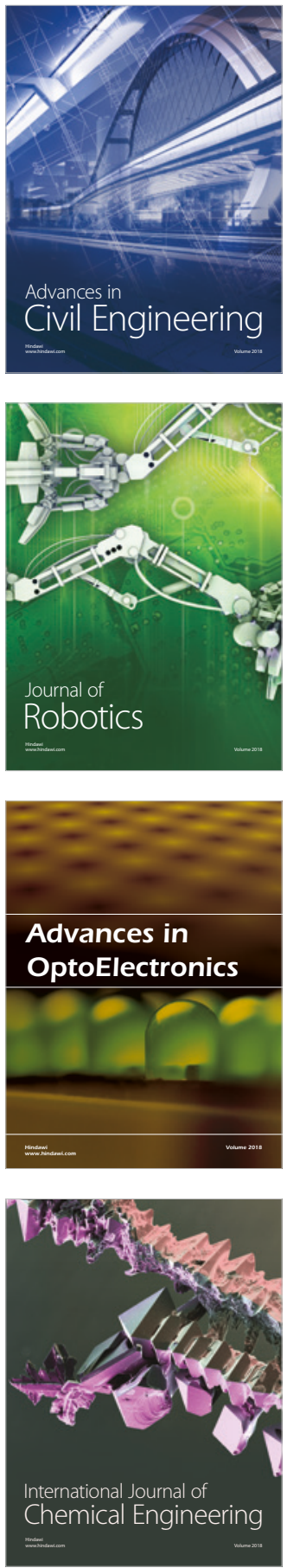

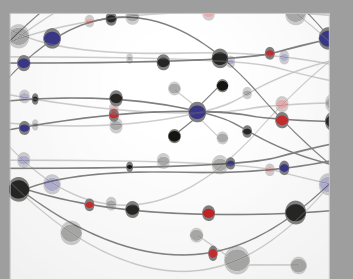

\section{Rotating \\ Machinery}

The Scientific World Journal

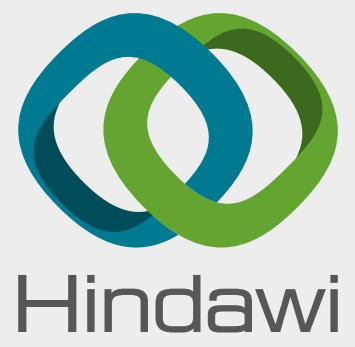

Submit your manuscripts at

www.hindawi.com
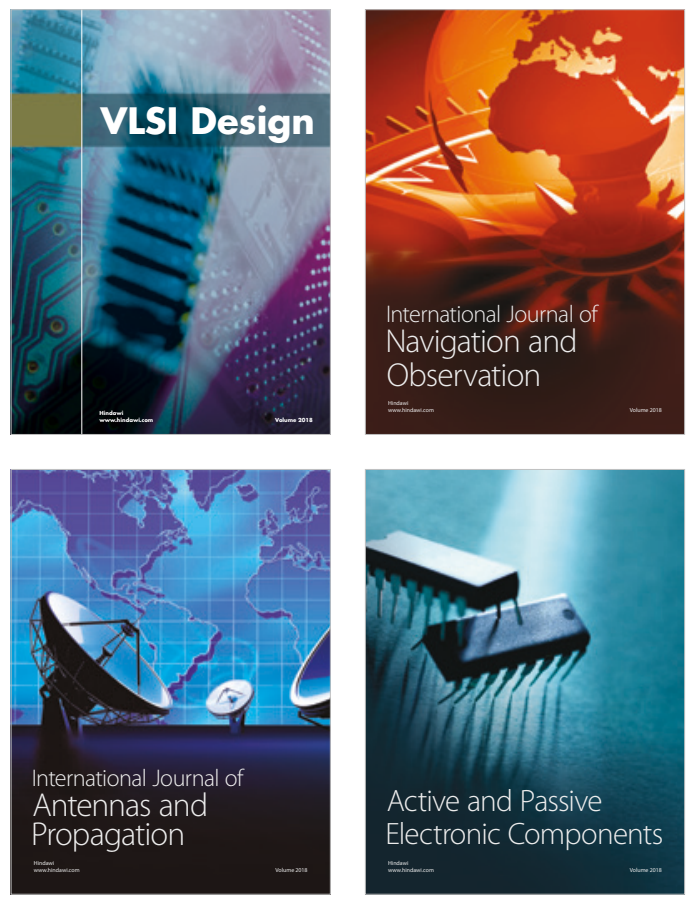
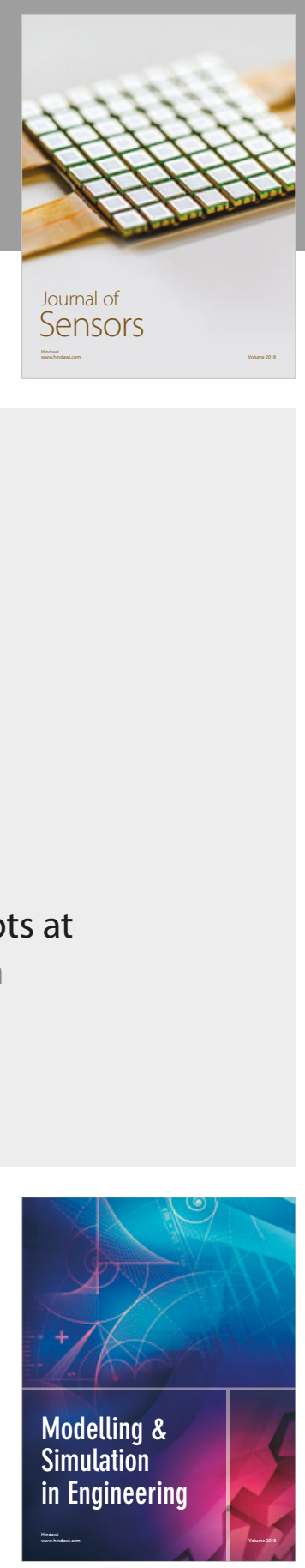

\section{Advances \\ Multimedia}
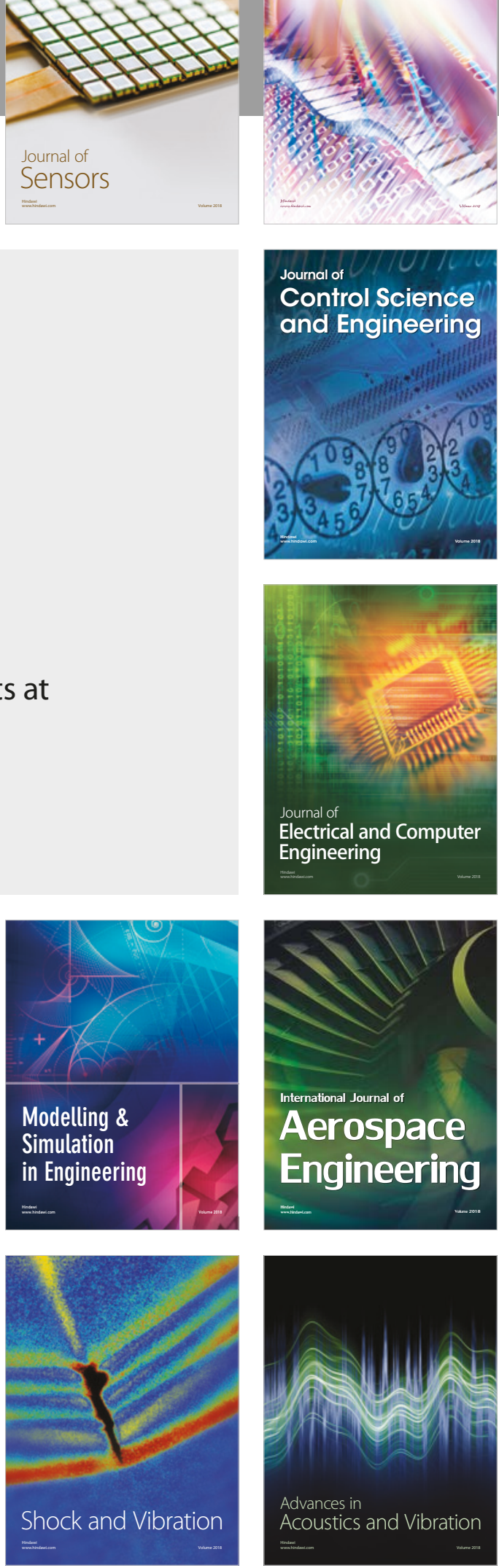